\title{
Validity of Zulliger-SC in the Cognitive Assessment of Elderly and Long-Lived Adults
}

\author{
Jucelaine Bier Di Domenico Grazziotin ${ }^{1}$ \\ Silvana Alba Scortegagna ${ }^{1}$ \\ ${ }^{1}$ University of Passo Fundo, Passo Fundo, Rio Grande do Sul, Brasil
}

\begin{abstract}
This study sought evidence of validity of the Zulliger method to evaluate cognitive processes in elderly and long-lived adults and to verify the relationship between cognition and external variables. Participated 142 subjects, aged between 18 and 96 years old. The Zulliger Comprehensive System (ZSC), Mini-Mental State Examination and sociodemographic protocols were used as of data collection. The older and long-lived adults presented a significant decrease in mediation $(\mathrm{X}-\%, \mathrm{XA} \%, \mathrm{P})$ and abstract reasoning $(\mathrm{M})$ when compared to young and middle-aged adults. Education and socioeconomic status (SES) demonstrated significant and positive correlations with cognitive processes (R, ZF, W, M, DQ+ and Intellectualization). The findings are fundamental to psychological practice and to directing measures for cognitive preservation in human aging.

Keywords: psychological assessment; projective techniques; adults; aging.
\end{abstract}

Validade do Zulliger-SC na Avaliação Cognitiva de adultos idosos e longevos

\begin{abstract}
Resumo
Esse estudo buscou evidências de validade do método de Zulliger para avaliar processos cognitivos em adultos idosos e longevos e verificar a relação entre cognição e variáveis externas. Participaram 142 indivíduos, com idades entre 18 e 96 anos. Utilizaram-se para a coleta de dados: Zulliger no Sistema Compreensivo (ZSC), Miniexame de Estado Mental e protocolo sociodemográfico. Adultos mais velhos e longevos apresentaram diminuição significativa na mediação (X-\%, XA\%, P) e raciocínio abstrato (M), comparados aos adultos jovens e de meia idade. A educação e o nível socioeconômico (NSE) demonstraram correlações positivas e significativas com processos cognitivos (R, ZF, W, M, DQ+ e Intelectualização). Os achados são fundamentais na prática psicológica e para direcionar medidas na preservação cognitiva no envelhecimento humano.

Palavras-chave: avaliação psicológica, técnicas projetivas, adultos, envelhecimento.
\end{abstract}

Validez de Zulliger-SC en la Evaluación Cognitiva de Adultos Mayores y Longevos

\begin{abstract}
Resumen
El presente estudio buscó evidencias de validez del método de Zulliger para evaluar procesos cognitivos en ancianos y longevos y para verificar la relación entre la cognición y las variables externas. Participaron 142 individuos con edades entre 18 y 96 años. Se utilizaron como instrumentos: Zulliger en el Sistema Comprensivo (ZSC), Mini Examen del Estado Mental y protocolos sociodemográficos. Ancianos y longevos presentaron una disminución significativa en la mediación (X-\%, XA\%, P) y el razonamiento abstracto (M) en comparación con los adultos jóvenes y de mediana edad. La educación y el nivel socioeconómico (NSE) demostraron correlaciones positivas y significativas con los procesos cognitivos (R, ZF, W, M, DQ+ e Intelectualización). Los hallazgos son fundamentales para la práctica psicológica y para dirigir medidas para la preservación cognitiva en el envejecimiento humano.

Palabras clave: evaluación psicológica; técnicas proyectivas; adultos; envejecimiento.
\end{abstract}

The proportion of the elderly is expanding rapidly worldwide. Comparisons between cohorts suggest that the debilitating effects of senescence are increasingly procrastinated to more advanced ages (Gerstorf et al., 2015). However, the advancement of adulthood continues to be associated with cognitive decline in many individuals, and major challenges remain in the understanding of the mechanisms of cognitive loss versus cognitive preservation or healthy aging.

Individual differences in age-related cognitive decline reflect an interaction between genetic and environmental factors (Cabeza et al., 2018; James et al.,
2018). In recent decades, the availability of magnetic resonance imaging (MRI) methods has advanced significantly in understanding how the brain changes with age at anatomical and functional levels. It is known, for example, that healthy aging is associated with volumetric reductions in gray matter and functional changes in several regions, which are crucial for superior cognitive function, the prefrontal cortices, (Cabeza, Nyberg, \& Park, 2017; Rajah, Maillet, \& Grady, 2015), and that changes occur in connectivity of the white matter between the prefrontal and posterior cortical regions and in the posterior sensory cortices (Madden et al., 
2010). These age-related declines in brain structure and function are associated with cognitive decline in various domains, including episodic memory, working memory, and attention (Lindenberger, 2014).

Although cognitive impairment may occur, some skills may improve and others may remain stable (Argimon, Irigaray, \& Stein, 2014; Cabeza et al., 2018; Shimitz \& Dorneles, 2013). Causal explanations for this are given, in part, by cognitive neuroscience studies of aging (Cabeza et al, 2017), through mechanisms related to reserve, maintenance and neurocognitive compensation. Briefly, reserve refers to the accumulation of brain resources over the useful life, maintenance concerns the preservation of these resources through constant recovery and repair, and compensation is the deployment of these resources in response to the demands of the tasks; in other words: reserve is about how much you have, maintenance is about how well you maintain it, and compensation is about when and how you use it (Cabeza et al., 2018).

Interindividual cognitive variability not only depends on age, but also on health conditions, lifestyle, ability to be optimistic when facing problems, participation in day-to-day activities, physical exercise and cognitive training (James et al., 2018; Meléndez, Mayordomo, \& Sales, 2013; Rowe \& Kahn, 1997). Education promotes cognitive reserve and attenuates cognitive decline related to aging (Argimon et al., 2014; Bertolucci, Brucki, Campacci, \& Juliano, 1994; Cabeza et al., 2018; Meléndez et al., 2013), both education and socioeconomic conditions cooperate so that the individual compensates for cognitive degradation, and uses more brain connection networks in cognitive maintenance (Gerstorf, Ram, Lindenberger, \& Smith, 2013). The combined action of high educational levels and the performance of occupational activities provide cognitive reserve that acts as a protection factor against the cognitive decline in aging (Cabeza et al., 2018; Meléndez et al., 2013; Zimmermann, Parente, Joanette, \& Fonseca, 2014).

In the early stages of life, there is an important cognitive development, whereas some decrease in fluid intelligence, abstract reasoning, short-term memory, and speed in information processing may occur in the middle age (Rueda \& Castro, 2013; Shimitz \& Dorneles, 2013). In contrast, the vocabulary is improved, the thinking becomes more flexible, and the middle-aged person can perceive various solutions to a single problem. It is a stage of great productions, entrepreneurship, in which the individual is more methodical and rational, and personality traits such as wisdom, which relate to the integrity of the ego, are more prone (Erikson 1998; Shimitz \& Dorneles, 2013).

In the elderly and long-lived adults, differences in individual cognitive abilities tend to become more pronounced, especially since the aging process is very heterogeneous. Just as it can be observed in verbal fluency, attention, memory (Argimon et al., 2014; Zimmermann et al., 2014), reasoning and processing of information, and planning and agility in the solution of tasks (Köstering, Stahl, Leonhart, Weiller, \& Kaller, 2014; Meléndez et al., 2013). However, it is important to consider that an optimal level of intellectual functioning, productivity and problem-solving ability can be found, because the experience and information accumulated over time become more prominent (Argimon et al., 2014; Erikson, 1998).

Although it cannot be generalized, in long-lived adults, the decline of cognitive functions may also be associated with experiences of functional losses, constant threats to the exercise of autonomy, loss of loved ones and proximity to finitude (Gerstorf et al., 2013). Other skills such as verbal fluency, memory, attention, and concentration may demonstrate a noticeable decrease (Argimon et al., 2014), as well as the ability to plan and abstract reasoning (Meléndez et al., 2013). The aging requires more and more effort to maintain a high level of intellectual functioning, it may be more difficult to memorize and retrieve information and seek out information that aids in problem solving, part of this may be a reflection of the basic loss in processing speed (Meléndez et al., 2013; Salthouse \& Ferrer-Caja, 2003).

Evaluating these changes is a complex but necessary task so that the aging population can be guaranteed quality of life, in order to subsidize means to intervene preventively against dementias. Considering the comprehensiveness of cognitive and personality assessment (Muzio, 2016), to attend to this need, the projective method of the Zulliger Comprehensive System (ZSC) (Villemor Amaral \& Primi, 2009) can be a potential tool for assistance.

The ZSC was introduced in Brazil by VillemorAmaral and Primi (2009). It is considered a method of self-expression because it allows one to indirectly obtain information about the psychic functioning of the individual, through a complex system of analysis of responses that involve concepts of psychometry and projection. The Structural Summary includes seven groupings of variables, three of them related to cognitive functioning. 
Cognitive processes refer to how people capture and process information, how they perceive the environment, their experiences, and the impressions of the events of their lives (processing, mediation, and ideation), adapting best when they can reason in a coherent way. Thus, the grouping of information processing in the ZSC concerns the cognitive aspects involved in the input of the stimulus, actions that operate on the way the message is received, to which elements people direct the attention and how they process the stimuli. The information processing variables include organizational activity $(Z f)$, global responses $(W)$, detail $(D)$ and uncommon detail $(D d)$, human movement responses $(M)$, perseveration (PSV), synthesized $\left(D Q^{+}\right)$and vague (DQv) responses (Villemor Amaral \& Primi, 2009).

The mediation grouping informs the cognitive functioning regarding the processing and the translation of the information. It indicates the degree of adaptability and the perception of the individual on the environment in which he lives and how he guides his actions in the environment. They include appropriately extended responses $(X A \%)$, appropriately in common areas $(W D A \%)$, conventional $(X+\%)$, distorted $(X-\%)$, unusual $(X u \%)$, white space with negative formal quality $(S-\%)$, and popular responses $(P)$ (Villemor Amaral $\&$ Primi, 2009).

The ideation grouping indicates whether people think logically and coherently, or whether there are indicators of thought disturbance, or whether they are permeated by concerns about the experiences and impressions of events in their lives. The variables of the ideation grouping include active $(a)$ and passive $(p)$ movement, active $(M a)$ and passive $(M p)$ human movement, intellectualization index $[2 A B+(A r t+A y)]$, morbid content (MOR), sum of special critical scores (Sumb), weighted sum of special critical scores (WSumb), human movement with distorted formal quality $(M-)$, human movement without form ( $M$ none). In addition to the cognitive triad variables, the number of responses $(\mathrm{R})$ and pure form responses $(\mathrm{F} \%)$ that are part of the ZSC resource and control grouping are important indicators of cognitive ability (Villemor Amaral \& Primi, 2009).

Some studies have demonstrated the contributions of the ZSC and the limitations of its use in the personality assessment, both at the international level (Aguilar \& Graso, 2015; Carpio \& Lugón, 2011; Contreras-Milián, González-Pérez, \& Herrera-Espinosa, 2016) as well as in the Brazilian context (Cardoso, Gomes, Pacheco, \& Viana, 2018; Grazziotin \& Scortegagna, 2016a; 2016b; 2018; Gregoletti \& Scortegagna, 2017; Miguel, Zuanazzi, \& Villemor- Amaral, 2017; Rien, Scortegagna, Grazziotin, \& Bertolin, 2017). However, studies that address cognition in healthy adults (Grazziotin \& Scortegagna, 2016a; 2018) and those that include older and long-lived adults are rare (Aguilar \& Graso, 2015; Grazziotin \& Scortegagna, 2018).

Aguilar and Graso (2015) evaluated the cognitive functioning of elderly and long-lived adults using ZSC and neuropsychological instruments (MMSE, clocks test). The sample consisted of 28 individuals from the Argentina, of both genders, aged between 60 and 85 years $(M=73.0)$, with a high education level. The results showed normality in the neuropsychological assessment and values similar to normative data of adults up to 55 years (XA\%, X-\%, Ma:Mp, MOR,WSum6). The authors emphasize the need to follow up studies with the older population, especially due to their heterogeneity and the influence of high education level in the sample studied.

Some investigations have sought to evidence the validity of ZSC by analyzing the influence of cultural elements on cognitive and personality assessment. Considering Brazilian cultural diversity, Grazziotin and Scortegagna (2016a) sought the validity of ZSC to evaluate information identification/translation processes, mediation variables, with samples of healthy adults from different Brazilian states. A total of 40 individuals of both genders participated, with ages varying between 18 and 43 years $(M=26.50)$ and all of them with high school education level, in the state of Rio Grande do Sul. The descriptive and comparative statistical analyses between groups of adults from the State of Rio Grande do Sul and normative data of Brazilians from the State of São Paulo showed statistically significant differences. There was an increase of $X A \%, W D A \%, X+\%$ and lowering of $X-\%$ and $S$ - in the Rio Grande do Sul State group, confirming qualities of social adaptation, adjustment to reality, objectivity and conservatism, characteristics of this group. The authors considered the need to continue studies of this nature with expanded and diversified samples to ensure that the established norms are appropriate for the population.

Considering the relevance of instruments for psychological assessment in the elderly, Grazziotin and Scortegagna (2018) sought evidence of convergent validity of the interpersonal relationship and cognitive triad indicators of the ZSC with the Social Skills Inventory for the Elderly (IHSI-Del-Prette; Del Prette 
\& Del Prette, 2001) with semantic and content adaptations (Carneiro et al., 2007; Scheufler et al.,2016). The study comprised 78 elderly, non-patients, between 60 and 96 years $(M=76.07)$. Among the results, the ZSC cognitive triad (R, D, XA\%, S-, X+\%) showed a significant and positive correlation of low magnitude with the general G score and the IHSI Del-Prette factors (F4/Sexual affective self-exposure, F2/Assertiveness of confrontation, F3/ Conversation and social entrepreneurship and F1/Emotional expressiveness). The study evidenced the convergent validity of the ZSC with IHSI-Del-Prette, enriching the understanding of the interpersonal relationship and the cognitive aspects of the elderly.

Researches with instruments in the area of psychological evaluation are extremely important, since professionals usually infer interpretations and make decisions, based on the results obtained. The quality of the evaluations is strongly tied to the evidence of validity of the instruments (Meyer, Giromini, Viglione, Reese \& Mihura, 2015; Primi, Muniz \& VillemorAmaral, 2009). Valid instruments need to accumulate evidences that certify the relevance of the test, its usefulness in the proposed uses and the interpretations generated (AERA, APA \& NCME, 2014). Also, the characteristics of the individuals, such as age, education, socioeconomic status (SES) (Primi et al., 2009) should be respected. Assuming that elderly and longlived adults differ in cognitive abilities when compared to younger adults, the following hypotheses related to ZSC variables were listed.

Hypothesis 1. If in the higher age groups cognitive resources tend to weaken (Argimon et al., 2014; Cabeza et al., 2018, Gerstorf et al., 2013, Meléndez et al., 2013, Köstering et al., 2014; Shimitz \& Dorneles, 2013) therefore: a) ZSC variables, which can inform about the cognitive adjustment (X+\%, XA\%, DQ+, Zf, R, P, $\mathrm{M}, \mathrm{a}, \mathrm{Ma})$ can significantly decrease in the elderly, and in the long-lived, when compared to young and middle-aged adults; b) ZSC variables, which may inform cognitive limitation $(\mathrm{X}-\%, \mathrm{Xu} \%, \mathrm{~S}-\%$, PSV, DQv, F\%, Sum6, WSum6,) may increase, especially in the longlived, when compared to young and middle-aged adults. On the other hand, if, as age advances, people tend to accumulate more life experiences (Erikson, 1998), then the variables $\mathrm{W}, \mathrm{WDA} \%$ and the intellectualization index $[2 \mathrm{AB}+(\mathrm{Art}+\mathrm{Ay})$ are higher in elderly and longlived adults.

Hypothesis 2. If external variables such as education level (Argimon et al., 2014, Bertolucci et al., 1994;
Cabeza et al., 2018; Melendez et al., 2013) and the SES (Gerstorf et al., 2013) may interfere in the cognitive capacity, then a) the ZSC variables that can inform about the cognitive adjustment (XA\%, X+\%, DQ+, Zf, R, P, $\mathrm{M}, \mathrm{a}, \mathrm{Ma})$, may be significantly and negatively associated in adults with lower level of education and SES; b) variables that report on cognitive limitations $(\mathrm{X}-\%, \mathrm{Xu} \%$, $\mathrm{S}-\%$, PSV, DQv, F\%) will present significantly and positively associated in adults with lower level of education and SES; c) the W and WDA\% variables that are indicative of intellectual wisdom, leadership or ambition, and the intellectualization index $[2 \mathrm{AB}+(\mathrm{Art}+\mathrm{Ay})]$ will be significantly and positively associated in adults with a higher level of education and SES.

Considering the above, the present study aimed to verify the evidences of validity of the ZSC to evaluate cognitive processes in elderly and long-lived adults and verify the relationship between cognition and external variables. The aim is to determine if there is a relationship between education level and SES with cognitive processes.

\section{Method}

\section{Participants}

The sample consisted of 142 healthy individuals, between 18 and 96 years of age, paired in gender in each group, living in the State of Rio Grande do Sul, Brazil. Participants were divided into four groups contemplating different stages of development (Erikson, 1998). The first group consisted of 30 Long-lived adults aged 80-96 years $(M=84.23, S D=3.69)$, with socioeconomic status belonging to class $\mathrm{C} 1(60 \%)$ and B2 $(23.30 \%)$, with average education level of 6 years $(S D=3.60)$. The second group consisted of 48 elderly adults aged between 60 and 79 years $(M=67.62 ; S D$ $=5.46$ ), with socioeconomic status belonging to class $\mathrm{C} 1(50 \%)$ and B2 (27.10\%), average education level of 7 years $(S D=4.01)$. The third group consisted of 32 middle-aged adults aged between 30 and 59 years $(M=$ 39.34; $S D=7.59)$, with socioeconomic status belonging to class C1 (68.8\%) and C2 (21.90\%), with an average education level of 9.5 years $(S D=2.09)$. The fourth group consisted of 32 young adults between 18 and 29 years of age $(M=20.94, S D=2.99)$, with socioeconomic status belonging to class $\mathrm{C} 1(56.30 \%)$ and $\mathrm{C} 2$ $(37.50 \%)$, with an average education level of 10 years $(S D=2.74)$.

Inclusion criteria for elderly adults were 60 years of age and older, who participated in social groups 
in different geographical areas of the city and nearby cities. The social groups are organized by the municipal public authority and offer actions to promote the quality of life and exercise of citizenship to the elderly community. The University of Passo Fundo also offers more than 20 permanent workshops, which aim to discuss issues about human aging through educational activities of an interdisciplinary nature, addressed to the community, at the Center for Reference and Care for the Elderly (CREATI).

For individuals up to 60 years of age, those who worked with customer service in supermarkets were considered, these being employees, suppliers, sales promoters. The participants performed psychological and medical evaluations, and were considered fit to be admitted to the company. For all study participants, the exclusion criteria were: (a) presence of a history of psychiatric treatment in the last six months; (b) history of stressful situations resulting from the diagnosis of illness or physical incapacity in the last six months; (c) experience any major loss that has caused suffering in the last six months; (d) have cognitive deficits; (e) present a hearing deficit that would compromise the communication; (f) demonstrate visual impairment that would interfere with the performance of the tests. These data were obtained through the administration of the sociodemographic and health characterization protocol and the Mini Mental State Exam (MMSE).

\section{Instruments}

Sociodemographic and health characterization protocol: elaborated by the study's researchers to obtain information about age, gender, marital status, education level, socioeconomic class, profession or occupation, health conditions, and verify the inclusion/ exclusion criteria of the sample. The economic class was evaluated by the Brazilian Economic Classification Criterion (CEBB) based on the Socioeconomic Status Survey (SES), effective as of 2015 - IBOPE (Associação Brasileira de Empresas de Pesquisa [ABEP], 2016).

Mini Mental State Examination (MMSE; Folstein, Folstein, \& McHugh, 1975) translated and validated in Brazil by Bertolucci et al. (1994), aimed to evaluate cognitive aspects and verify the inclusion and exclusion criteria of the sample. It is composed of questions grouped into seven categories, with a total score of 0 to 30 points. The cut-off points of the Brucki, Nitrini, Caramelli, Bertolucci and Okamoto (2003) study were used: (a) low education level (1 to 4 years) - 21 points; (b) average education level (4 to 8 years) - 24 points; (c) high education level (above 8 years) - 26 points.

Zulliger's method in the Comprehensive System (ZSC; Villemor-Amaral \& Primi, 2009): it allows the interpretation of personality dynamics and cognitive processes. The test consists of a set of three cards that contains the design of a different and symmetrical inkblots for each of them. Inkblots have characteristics of ambiguity and incompleteness that stimulate the person to give configuration to the stimulus. The administration is carried out in two stages: first, the participants respond to what they think of the inkblots, having done this on the three cards, inquiry is conducted on where they viewed their response on the card, and what gave them the idea of what was seen. In view of the proposed objectives and the hypotheses outlined in this study, cognitive triad variables related to information processing, mediation and ideation were selected.

\section{Procedures}

After obtaining the letter of approval from the institutions and approval of the study by the Ethics Committee of the University, data collection began. Participants were intentionally selected, those aged 18 to 59 were referred by the managers of the supermarket stores, and those aged 60 and over were led by the coordinators of the social groups. Those who agreed to participate in the research signed the Free and Informed Consent Term, and responded to the instruments individually, in the dependencies of the relevant institutions. Initially, the sociodemographic and health characterization protocol was administered and, subsequently, the ZSC. Participants aged over 60 also responded to the MMSE. The time for the application of the instruments was one hour and thirty minutes.

For reliability of the ZSC data, an inter-rater reliability study was conducted. $25 \%$ of the protocols were drawn and sent to recode by an independent judge, after which the Kappa coefficient analysis was performed. Values above 0.78 were obtained for all variables of the test. Such a coefficient of accuracy reveals a good index of reliability (Landis \& Koch, 1977).

\section{Data analysis}

The data were stored in Excel spreadsheet, and for statistical analysis, SPSS 22.0 for Windows was used. In order, to compare ZSC variables between the groups of individuals distributed in four age groups (80 to 96 years, 60 to 79 years, 30 to 59 years and 18 to 29 years), the analysis of variance was used with one classification 
criteria. Pairwise comparisons were performed using Fischer's LSD. When the variance between the different groups was significantly heterogeneous, the probability value was estimated using the Welch Robust estimator. Pairwise comparisons were performed using Games Howell's post-hoc test. Statistically significant tests with a probability value $<0.05$ were considered. After, to verify the occurrence of association between the ZSC cognitive triad variables with SES and education level, Pearson's correlation was used.

Ethical Considerations. The study was approved by the Research Ethics Committee of the University, under Report (CAAE:40295220.10000.5342). It includes Resolutions 510/2016 of the National Health Council and 09/2018 of the Federal Council of Psychology.

\section{Results}

Considering the objective of the study it was sought to verify in which stage of adult life the decrease or increase of the cognitive triad variables in the ZSC had occurred. Thus, Table 1 describes the comparisons of ZSC variables among different age groups (Erikson, 1998): a) Long-lived adults (80 years and over); b) Elderly adults (60 to 79 years); c) Adults of middle age (30 to 59 years); d) Young adults (18 to 29 years).

There was a statistically significant difference between $R(p=0.009), X A \%(p=0.019), X-\%$ $(\mathrm{p}=0.033), S-(p=0.005), P(p=0.011), M a(p=$ 0.005). Specifically in elderly adults (60 to 79 years), $R$ values were significantly higher than in long-lived adults (80 years and over); the variable $X_{-} \%$ was significantly higher than in young adults (18 to 29 years) and middle-aged adults (30 to 59 years); the $S$ - showed significantly higher values than in young adults, middle-aged adults and than the long-lived adults. Elderly adults presented significantly lower values in $M a$ when compared to young adults. The variable $X A \%$ was significantly lower than in young and middle-aged adults. Specifically in Long-lived adults, $X-\%$ had significantly higher values than middle-aged adults. $X A \%$ showed significantly lower values than middle-aged adults. The variable $\mathrm{P}$ was significantly lower when compared to young adults. Long- lived adults presented significantly lower values in $M a$ when compared to young adults.

In addition to the comparisons between the ZSC cognitive variables in the elderly and long-lived adults with younger age groups, the authors sought to verify the association between external variables (SES and education level) and cognition. Table 2 shows the correlation of the ZSC cognitive triad variables with SES and Education level.

It can be observed that there was a significant positive and low correlation of the variables $R, Z F$, $W, M, D Q^{+}$, and Intellectualization of ZSC with SES. Regarding education level, a significant positive and low correlation was observed with the variables $Z F, W$, $D Q+, X A \%, W D A \%, P$ and $a$ significantly positive and moderate with the variable $M a$. A significant negative and low correlation of the variable $X_{-} \%$ with education level was also verified.

\section{Discussion}

The results indicate evidence of validity of the ZSC to evaluate cognitive processes in the elderly and long-lived adults when compared to younger and middle-aged adults. Differences were observed in the four groups studied, as well as due to the influence of education level and SES. It is understood that as the course of life progresses, the individual tends to make greater cognitive effort (Cabeza et al., 2018) using intellectual knowledge and life experiences, which may be permeated by perceptions and unconventional thoughts (Villemor Amaral \& Primi, 2009). These resources help to neutralize the impact of negative experiences such as existential dilemmas, health problems and problems related to functionality and autonomy, affective problems because of mourning, and thus maintain ego integrity in the face of death (Erikson, 1998; Gerstorf et al., 2013, Meléndez et al., 2013).

It is difficult to determine at what stage of adult life cognitive limitations begin to occur. Some authors agree that young and middle-aged adults are at the peak of productive cognitive abilities (Shimitz \& Dorneles, 2013) and have a low probability of perceptual distortion (Meyer et al., 2015). From that point on, older adults show great variability, with a greater propensity for cognitive decline related changes (Cabeza et al., 2018; James et al., 2018). Thus, the significant differences found in the ZSC will be discussed, using analysis of variance, considering older and long-lived adults in comparison with younger adults.

The variable $R$ is related to productivity, energy and motivation. The analysis of variance showed a significant increase of $\mathrm{R}$ in elderly adults and a decrease in the long-lived. This finding seems to partially corroborate with the initial hypothesis of this study. A possible explanation for increased productivity in the elderly is 
Table 1.

Comparison of ZSC cognitive triad variables of elderly and long-lived adults among younger age groups $(n=142)$

\begin{tabular}{|c|c|c|c|c|c|c|c|c|c|}
\hline & \multicolumn{4}{|r|}{ Age } & \multicolumn{4}{|l|}{ Groups } & \\
\hline & $80-96$ & years & $60-79$ & years & $30-59$ & years & $18-29$ & \multicolumn{2}{|l|}{ years } \\
\hline Zulliger & M & $\mathrm{SD}$ & $\mathrm{M}$ & $\mathrm{SD}$ & M & $\mathrm{SD}$ & $\mathrm{M}$ & SD & $\mathrm{p}$ \\
\hline $\mathrm{R}$ & 7.20 & 2.29 & 9.77 & 4.13 & 8.00 & 2.31 & 8.25 & 2.38 & $0.009 * *$ \\
\hline $\mathrm{Zf}$ & 3.03 & 1.47 & 4.13 & 2.20 & 3.60 & 1.47 & 3.53 & 1.29 & 0.081 \\
\hline W & 1.27 & 0.94 & 1.58 & 1.08 & 1.81 & 1.33 & 1.47 & 1.27 & 0.302 \\
\hline M & 0.70 & 0.91 & 0.71 & 1.05 & 0.81 & 0.86 & 1.19 & 0.89 & 0.121 \\
\hline PSV & 0.47 & 0.68 & 0.21 & 0.41 & 0.16 & 0.37 & 0.13 & 0.33 & 0.105 \\
\hline DQv & 0.50 & 0.68 & 0.48 & 0.87 & 0.41 & 0.71 & 0.53 & 0.84 & 0.934 \\
\hline $\mathrm{DQ}^{+}$ & 1.70 & 1.05 & 2.19 & 1.67 & 2.09 & 1.14 & 1.97 & 1.09 & 0.384 \\
\hline $\mathrm{XA} \%$ & 77.39 & 15.94 & 76.06 & 14.09 & 84.96 & 12.89 & 82.36 & 11.16 & $0.019 *$ \\
\hline WDA\% & 71.68 & 17.98 & 71.60 & 17.81 & 75.44 & 16.16 & 74.00 & 15.05 & 0.732 \\
\hline $\mathrm{X}-\%$ & 21.43 & 15.93 & 21.94 & 12.86 & 14.57 & 12.12 & 16.08 & 10.29 & $0.033^{*}$ \\
\hline $\mathrm{Xu} \%$ & 25.65 & 18.29 & 29.12 & 16.11 & 29.23 & 13.22 & 28.36 & 15.91 & 0.786 \\
\hline S- & 0.20 & 0.41 & 0.54 & 0.62 & 0.16 & 0.37 & 0.19 & 0.39 & $0.005^{* *}$ \\
\hline $\mathrm{X}+\%$ & 52.40 & 21.57 & 46.73 & 20.87 & 52.78 & 17.92 & 52.99 & 18.66 & 0.412 \\
\hline $\mathrm{F} \%$ & 50.47 & 25.86 & 46.52 & 17.98 & 37.60 & 23.50 & 42.63 & 18.82 & 0.102 \\
\hline $\mathrm{P}$ & 0.93 & 0.94 & 1.17 & 0.83 & 1.50 & 0.88 & 1.63 & 1.00 & $0.011^{*}$ \\
\hline a & 0.87 & 0.86 & 1.35 & 1.21 & 1.34 & 1.18 & 1.41 & 1.13 & 0.196 \\
\hline $\mathrm{p}$ & 0.97 & 1.21 & 0.98 & 1.10 & 1.16 & 1.39 & 1.00 & 1.13 & 0.912 \\
\hline $\mathrm{Ma}$ & 0.33 & 0.55 & 0.44 & 0.71 & 0.56 & 0.76 & 0.91 & 0.64 & $0.005^{* *}$ \\
\hline $\mathrm{Mp}$ & 0.37 & 0.67 & 0.35 & 0.73 & 0.22 & 0.49 & 0.38 & 0.70 & 0.754 \\
\hline$[2 \mathrm{AB}+(\mathrm{Art}+\mathrm{Ay})]$ & 1.37 & 1.59 & 1.29 & 1.40 & 0.94 & 1.10 & 0.81 & 1.12 & 0.247 \\
\hline MOR & 0.25 & 0.51 & 0.25 & 0.48 & 0.41 & 0.56 & 0.25 & 0.51 & 0.370 \\
\hline Sum6 & 0.31 & 0.47 & 0.56 & 0.68 & 0.47 & 0.57 & 0.31 & 0.47 & 0.253 \\
\hline WSum6 & 0.78 & 1.29 & 1.38 & 2.20 & 1.19 & 1.61 & 0.78 & 1.29 & 0.253 \\
\hline \multicolumn{3}{|c|}{ Comparison of GROUPS } & \multicolumn{2}{|c|}{ ZSC } & \multicolumn{2}{|c|}{ MD CI95\% } & & \multicolumn{2}{|c|}{$\mathrm{p}$} \\
\hline \multicolumn{3}{|c|}{ Long lived x Elderly } & \multicolumn{2}{|c|}{$\mathrm{R}$} & \multicolumn{2}{|c|}{$-2,60(0,70-4,50)$} & & \multicolumn{2}{|c|}{0.004} \\
\hline \multicolumn{3}{|c|}{ Long lived x Middle age } & \multicolumn{2}{|c|}{$\begin{array}{l}\mathrm{XA} \% \\
\mathrm{X}-\%\end{array}$} & \multicolumn{2}{|c|}{$\begin{array}{r}-7,60(0,70-14,40) \\
6,90(0,37-13,34)\end{array}$} & & \multicolumn{2}{|c|}{$\begin{array}{l}0.031 \\
0.038\end{array}$} \\
\hline \multicolumn{3}{|c|}{ Long lived x Young } & \multicolumn{2}{|c|}{$\mathrm{P}$} & \multicolumn{2}{|c|}{$\begin{array}{l}-0,69(0,04-1,35) \\
-0,57(0,19-0,97)\end{array}$} & & \multicolumn{2}{|c|}{0.035} \\
\hline \multicolumn{3}{|c|}{ Elderly x Middle age } & \multicolumn{2}{|c|}{$\begin{array}{l}\mathrm{X}- \\
\mathrm{Ma}\end{array}$} & $\begin{array}{c}-8,90 \\
7,40 \\
0,39\end{array}$ & $\begin{array}{l}-15,10) \\
-13,20) \\
-0,68)\end{array}$ & & & \\
\hline
\end{tabular}

Note: $\mathrm{M}=$ mean $; \mathrm{DP}=\mathrm{MD}=$ mean difference $\mathrm{p}=$ probability value

that the interindividual cognitive variability not only depends on age, but also on accumulation of brain resources over the useful life (Cabeza et al., 2018; James et al., 2018), the experience and information accumulated over time can become more prominent (Argimon et al., 2014; Erikson, 1998) and the idea that the person 
Table 2.

Correlation of the ZSC cognitive triad with SES and education level

\begin{tabular}{ccccc}
\hline & \multicolumn{2}{c}{ SES } & \multicolumn{2}{c}{ Education level } \\
\cline { 2 - 5 } Zulliger & $\mathrm{r}$ & $\mathrm{p}$ & $\mathrm{r}$ & $\mathrm{p}$ \\
\hline $\mathrm{R}$ & 0.30 & $0.001^{* *}$ & 0.13 & 0.127 \\
Zf & 0.34 & $0.001^{* *}$ & 0.27 & $0.001^{* *}$ \\
$\mathrm{~W}$ & 0.23 & $0.005^{* *}$ & 0.27 & $0.001^{* *}$ \\
$\mathrm{M}$ & 0.22 & $0.010^{* *}$ & -0.03 & 0.726 \\
PSV & 0.11 & 0.177 & 0.06 & 0.463 \\
DQv & 0.01 & 0.994 & -0.05 & 0.503 \\
DQ+ & 0.25 & $0.003^{* *}$ & 0.19 & $0.025^{*}$ \\
XA\% & 0.10 & 0.218 & 0.29 & $0.001^{* *}$ \\
WDA\% & 0.14 & 0.090 & 0.19 & $0.020^{*}$ \\
X-\% & 0.349 & -0.27 & $0.001^{* *}$ \\
Xu\% & 0.07 & 0.076 & 0.10 & 0.208 \\
S- & 0.15 & 0.245 & 0.02 & 0.819 \\
X+\% & 0.10 & 0.989 & 0.09 & 0.264 \\
F\% & 0.01 & 0.587 & -0.16 & 0.059 \\
P & 0.05 & 0.843 & 0.39 & $0.001^{* * *}$ \\
a & 0.02 & 0.105 & 0.25 & $0.002^{*}$ \\
P & 0.14 & 0.175 & 0.02 & 0.793 \\
Ma & 0.01 & 0.608 & 0.45 & $0.001^{* * *}$ \\
[2AB + Art+Ay) & 0.04 & $0.035^{*}$ & 0.01 & 0.876 \\
\hline
\end{tabular}

Note: SES: Socioeconomic Status, r: correlation coefficient; p: probability value

develops during the whole course of life, being stimulated to form new cognitive connections (Cabeza et al., 2018; Meléndez et al., 2013; Shimitz \& Dorneles, 2013). However, the decrease in $R$ in the long-lived adult alludes to the understanding that even in healthy old age, where there is participation in day to day activities and social insertion, it is very likely that the long-lived adult present some decline of cognitive functions (Argimon et al., 2014; Cabeza et al., 2017, 2018; Meléndez et al., 2013). So, in long-lived adults, the decreased productivity and motivation for cognitive tasks may also be associated with experiences of functional losses, constant threats to the exercise of autonomy and proximity to finitude (Gerstorf et al., 2013).

The variables $X A \%$ and $X-\%$ inform whether the individual perceives reality in an objective and adequate way or tends to have mediational problems, the variable $P$ reports concern with the conventional. In $X A \%$, older adults showed worse results in assessing the perception of reality when compared to young adults. Elderly and long-lived adults presented lower adequacy in the use of the criterion of reality when compared to middle-aged adults. In $X-\%$, elderly and long-lived adults have been shown to distort reality more seriously and to interpret the actions and intentions of others more inappropriately and with less critical judgment when compared to young and middle-aged adults. In $P$, long-lived adults had lower social adequacy and acceptance of standards when compared to young adults. These results confirm previous hypotheses in this study, and the idea that in old age the person may present difficulties in the planning of tasks (Köstering et al, 2014), in the organization of ideas, thoughts and logical and conventional reasoning (Argimon et al., 2014; Gerstorf et al., 2013).

As expected, in the $M a$ variable, the elderly and the long-lived had significantly lower values than the young adults did. This finding points to the possibility that older people may exhibit less active behavior, have little initiative and independence difficulty in problem 
solving (Erikson, 1998; Gerstorf et al., 2013; Köstering et al., 2014) while young adults may be more focused on practical solutions of daily life with a tendency to more rapid information processing (Rueda, \& Castro, 2013; Shimitz \& Dorneles, 2013).

The $S$ - variable presented significantly higher values in elderly adults when compared to the long-lived, middle-aged and young adults. This result supports the understanding that older adults have the predominant theme of the dilemma between ego integrity and despair (Erikson, 1998; Shimitz \& Dorneles, 2013). When the perceptual capacity of an individual is more subject to emotional interference, as in stressful situations, there may be mistaken thoughts about reality, which interferes with cognitive abilities (Meyer et al., 2015; Villemor-Amaral \& Primi, 2009).

The findings concerning the cognitive triad of ZSC indicate the importance of using the instrument with elderly and long-lived adults, because besides corroborating the hypotheses of this study, they provide insights into the cognitive structuring and psychic functioning of these individuals. As can be seen, the decrease in cognitive processes does not only result from the increase of age alone, but also from a multifactorial context, from the complex interaction between genetic and environmental factors that surround aging (Cabeza et al., 2018; Meléndez et al. 2013; Zimmermann et al., 2014).

Some variables such as $Z F, D Q+$ and $W$, which indicate perceptions involving more elaborate and creative cognitive effort as well as processes of abstraction and synthesis, and work motivation, did not show statistically significant differences with age, but showed positive and low significant correlations with education level and SES. These results corroborate the idea that education, together with health-related issues (Argimon et al., 2014; Cabeza et al., 2018; Cabeza et al., 2017; Meléndez et al., 2013; Rowe \& Kahn, 1997) and socioeconomic indicators (Gerstorf et al., 2013) can prevent and attenuate the cognitive decline due to aging.

In this line of reasoning, variables such as $X A \%$, $W D A \%, P, M a$, and a, showed positive association, however $X-\%$ denoted negative association, when correlated with education level. It can be said that the perception of reality, social adjustment and decision making tend to rise in the face of a higher level of education. This data corroborates Aguilar e Graso (2015) who verified the preserved cognitive conditions in older and healthy adults with high education level, evaluated by ZSC. The scores of the variables $\mathrm{R}, M$, and $[2 A B+$
$(A r t+A y)]$ correlated significantly with SES. This indicates that productivity, initiative, abstract reasoning and the use of mechanisms of intellectualization may rise in the face of better socioeconomic conditions. Therefore, these results corroborate the hypotheses of this study, that the variables that can inform about cognitive adjustment could be associated in people with higher education and SES.

As can be seen, the ZSC is an instrument that, through various groupings of variables, allows us to understand the dynamics of psychic functioning. In the comparison analysis of the 20 variables of ZSC listed in the hypothesis, six (30\%) showed to discriminate of significant form, groups of elderly adults and long-lived (R, XA\%, X-, S-, P, Ma ). In the analysis of the correlation of the 18 variables listed in the hypothesis, six (33\%) had significant association $\left(R, Z F, W, M, D Q^{+}\right.$ and Intellectualization) with SES and nine (50\%) had significant association $(Z F, W, D Q+, X A \%, W D A \%, P$ a Ma. X-\%) with education level.

In recent years, advances have been made in the studies with the ZSC at more advanced ages and in the investigation of the cognitive aspects (Aguilar \& Graso, 2015; Grazziotin \& Scortegagna, 2016a; 2018; Gregoletti \& Scortegagna, 2017; Miguel et al., 2017; Rien et al., 2017). However, research is insufficient (Cardoso et al.,2018; Grazziotin \& Scortegagna, 2016b), partly because the legitimacy of the information obtained with psychological tests depends, among other things, on empirical research that certifies the quality of the instruments and their applicability to the intended purposes (Markus \& Borboom, 2013). In addition to the self-report instruments, it is recommended to use selfexpression tools to deepen the understanding of the cognitive and psychic aspects (Contreras-Milián et al, 2016; Meyer et al., 2015; Muzio, 2016).

This study should be interpreted in light of its limitations. First, cohort effects (Trahan, Stuebing, Fletcher \& Hiscock, 2014) may contaminate the crosssectional nature of the dataset obtained. The second limitation of this study is the generalization of its findings. The results from a Western culture sample do not allow it to be transferred to other different cultures. Despite these limitations, it should be mentioned that it is always a great challenge to highlight the validity of instruments and to draw reliable and useful conclusions, supported by empirical methods (Meyer et al., 2015, Primi et al., 2009).

The present study demonstrated an accumulation of information that supports evidence of validity 
of the ZSC as a safe instrument capable of assessing cognitive abilities in elderly adults and differentiates them from younger adults, in addition to referring to individual differences and groups in adult life. The findings are valuable for psychological practice, especially those working with methods of psychological assessment and may be useful to motivate the development of actions that will potentiate the reservation, compensation and maintenance of the cognitive processes applied to aging.

Finally, follow up studies of evidence of ZSC validity in the cognitive evaluation of elderly and long-lived adults should be encouraged. Therefore, it is suggested to include enlarged samples of different age groups with different health conditions, from other regions of Brazil and from different cultures. This will require sufficient funding to support large, ideally longitudinal studies. Such research would be relevant to the field of psychology in the use of scientifically recommended evaluation instruments; in the multidisciplinary field to better understand cognitive changes related to age, variations in environmental and genetic factors for a given birth cohort; to address public health measures, education and the use of necessary technologies.

\section{References}

ABEP - Associação Brasileira de Empresas de Pesquisa (2016). Dados com base no Levantamento Sócio Econômico 2015. Retrieved from http://www.abep. org/criterio-brasil

Aguilar, M. J. G., \& Graso, L. (2015). Evaluación de una muestra de adultos mayores sanos de población general através del test de Zulliger-Sistema Comprehensivo. Psicodiagnóstico de Rorschach, 36(1), 45-71. Retrieved from http:// www.asoc-arg- rorschach.com.ar/revista/RevistaRorschach-dic-2015-Anio-36-N-1.pdf

American Educational Research Association [AERA], American Psychological Association [APA], Nacional Council on Measurement in Education [NCME] (2014). Standards for Educational and Psychological Testing. Washington, DC: American Educational Research Association.

Argimon. I. L., Irigaray, T. Q., \& Stein, L. M. (2014). Cognitive development across different age ranges in late adulthood. Universitas Psychologica, 13(1), 253 264. doi: 10.11144/ Javeriana.UPSY13-1.cdad
Bertolucci, P. H. F., Brucki, S. M. D., Campacci, S. R., \& Juliano, Y. (1994). O mini-exame do estado mental em uma população geral: impacto da escolaridade. Arquivos de Neuropsiquiatria, 52(1), 1-7. doi: 10.1590/S0004-282X1994000100001

Brucki, S. M. D., Nitrini, R., Caramelli, P., Bertolucci, P. H. F., \& Okamoto, I. H. (2003). Sugestões para o uso do Mini-Exame do Estado Mental no Brasil. Arquivos de Neuropsiquiatria, 61(3-B), 777-781. doi: 10.1590/S0004-282X2003000500014

Cabeza, R., Nyberg, L., \& Park, D. C. (2017). Cognitive Neuroscience of Aging: Linking Cognitive and Cerebral Aging 2nd ed New York: Oxford Univ. Press.

Cabeza, R., Albert, M., Belleville, S., Craik, F. I. M., Duarte, A., Grady, C. L., ... Rajah, M. N. (2018). Maintenance, reserve and compensation: the cognitive neuroscience of healthy ageing. Nature Reviews Neuroscience, 19,701-710 doi: 10.1038/ s41583-018-0068-2

Cardoso, L., Gomes, G., Pacheco, F., \& Viana, J. (2018). Análise da produção de artigos científicos brasileiros sobre o Teste de Zulliger. Interação em Psicologia, 22(3). doi: 10.5380/psi.v22i3.45821

Carneiro, R. S., Falcone, E., Clark, C., Del Prette, Z., \& Del Prette, A. (2007). Qualidade de vida, apoio social e depressão em idosos: Relação com habilidades sociais. Psicologia: ReAlexão e Crítica, 20(2), 229-237. doi:10.1590/ S0102-79722007000200008

Carpio, R. S., \& Lugón, C. M. (2011). Validación del Sistema Comprehensivo de Exner en el Test de Zulliger. Persona, 14, 145-158. Retrieved from http:// www.redalyc.org/pdf/1471/147122650006.pdf

Conselho Nacional de Saúde (2016). Resolução No 510, de 07 de abril de 2016. Brasilia, DF. Retrieved from http://conselho. saude.gov.br/ resolucoes/2016/ reso510. pdf

Conselho Federal de Psicologia - CFP. (2018). Resolução CFP No 09/2018. Brasília, DF. Retrieved from http://satepsi.cfp.org.br/docs/ Resolu\% C3\%A7\% C3\% A3o CFP - n\% C2 \%BA-09-2018com - anexo.pdf

Contreras-Milián, R. C. P., González-Pérez, M., Herrera-Espinosa, A. M. A. (2016). Identification of personality traits of the profile organizational psychologist in trainin, based on 
Zulliger Test. Europen Scientific Journal, 12(5),328339. doi:10.19044/esj.2016.v12n5p328

Del Prette, Z. A. P., \& Del Prette, A. (2001). Inventário de Habilidades Sociais (IHS - Del- Prette): Manual de aplicação, apuração e interpretação. São Paulo, SP: Casa do Psicólogo.

Erikson, E. H. (1998). The life cycle completed: A review. Extended version. New York: W.W. Norton \& Company Inc. (Original work published 1982).

Folstein, M. F., Folstein S. E., \& Mchugh, P. R. (1975). Mini-mental state: a practical method for grading the cognitive state off patients for the clinician. Journal of Psychiatric Research, 12, 189-198. Retrieved from https://www.ncbi.nlm.nih.gov/ pubmed/1202204

Grazziotin, J.B.D.D., \& Scortegagna, S.A. (2016a). Mediação no Zulliger: Evidências de validade na amostra de pacientes. Psico-USF, 21(1), 63-72. doi: 10.1590/1413-82712016210106

Grazziotin, J.B.D.D, \& Scortegagna, S. A (2016b). Revisão de pesquisas brasileiras sobre o Teste de Zulliger publicadas em artigos. Avaliação Psicológica, 15(2), 227-235. doi:10.15689/ap.2016.1502.11

Grazziotin, J.B.D.D, \& Scortegagna, S. A (2018). Convergent Validity of Zulliger-CS with the Social Skills Inventory for the Elderly. Paidéia (Ribeirão Preto), 28, e2832. doi; 10.1590/1982-4327e2832

Gregoleti, V., \& Scortegagna, S. A. (2017). The Zulliger-CS in Elderly on Hemodialysis and the Relationship Between External Variables. Paidéia (Ribeirão Preto), 27(66), 43-50. doi: 10.1590/198243272766201706

Gerstorf, D., Ram, N., Lindenberger, U., \& Smith, J. (2013). Age and Time-to-Death Trajectories of Change in Indicators of Cognitive, Sensory, Physical, Health, Social, and Self - Related Functions. Developmental Psychology, 49(10), 1805-1821. doi: 10.1037a003 1340

Gerstorf, D., Hülür, G., Drewelies, J., Eibich, P., Duezel, S., Demuth, I.,... Lindenberger, U. (2015).Secular changes in late- life cognition and well- being: towards a long bright future with a short brisk ending? Psychology and Aging, 30(2), 301-310. doi: $10.1037 / \mathrm{pag} 0000016$

James, S.-N., Davis, D., O’Hare, C., Sharma, N., John, A., Gaysina, D., ... Richards, M. (2018). Lifetime affective problems and later-life cognitive state: Over 50 years of follow- up in a British birth cohort study. Journal of Affective Disorders, 241, 348355. doi:10.1016/j.jad.2018.07.078

Köstering, L., Stahl, C., Leonhart, R., Weiller, C., \& Kaller, C.P (2014). Development of Planning Abilities in Normal Aging:Differential Effects of Specific Cognitive Demands. Developmental Psychology, 50(1), 293-303. doi: 10.1037/a0032467

Landis, J. R., \& Koch, G.G (1977). The measurement of observer agreement for categorical data. Biometrics, 33(1), 159 - 174. doi:10.2307 / 2529310

Lindenberger, U. (2014). Human cognitive aging: Corriger la fortune? Science, 346(6209), 572-578. doi:10.1126/science. 1254403

Madden, D. J., Costello, M. C., Dennis, N. A., Davis, S. W., Shepler, A. M., Spaniol, J., ... Cabeza, R. (2010). Adult age differences in functional connectivity during executive control. NeuroImage, 52(2), 643- 657. doi:10.1016/ j.neuroimage. 2010. 04.249

Markus, K.A., \& Borboom, D. (2013). Frontiers of test validity theory: Meansurement, causation, and meaning (Multivariate Applications Series). New York, NY: Routledge.

Meléndez, J. C., Mayordomo, T., \& Sales, A. (2013). Comparación entre ancianos sanos con alta y baja reserva cognitiva y ancianos con deterioro cognitivo. Universitas Psychologica, 12(1), 73-80. Retrieved from http://www.scielo.org.co/pdf/rups/v12n1/ v12n1a08.pdf

Meyer, G. J., Giromini, L., Viglione, D. J., Reese, J. B., \& Mihura, J. L. (2015). The Association of Gender, Ethnicity, Age, and Education With Rorschach Scores. Assessment, 22(1) 46-64. doi: $10.1177 / 1073191114544358$.

Miguel, F. K., Zuanazzi A. C., \& Villemor-Amaral, A. E. (2017). Assessment of Emotional Intelligence Aspects in the Methods of Pfister's and Zulliger's. Trends in Psychology, 25(4), 1853-1862. doi:10.9788/ TP2017.4-17Pt

Muzio, E. (2016). Inkblots and Neurons Correlating Typical Cognitive Performance With Brain Structure and Function. Rorschachiana, 37(1), 1-6 doi:10.1027/1192-5604/a000073

Primi, R., Muniz, M. E., \& Villemor-Amaral, A. E. (2009). Validade do Zulliger no Sistema Compreensivo. 
In: A.E. Villemor-Amaral \& R. Primi (Orgs.). Teste de Zulliger no Sistema Compreensivo ZSC: forma (pp. 137-170). São Paulo: Casa do Psicólogo.

Rajah, M. N., Maillet, D. \& Grady, C. L. (2015). Episodic Memory in Healthy Older Adults:The Role of Prefrontal and Parietal Cortices. In D.R. Addis, M. Barense, \& A. Duarte, (eds.). The Wiley Handbook of Cognitive Neuroscience of Memory (pp. 347-361). New York, Wiley Publishers.

Rien, M., Scortegagna, S. A., Grazziotin, J. B.D.D., \& Bertolin, T.E. (2017). Validity evidence of the Zulliger- CS in older adults with Parkinson's disease. Estudos de Psicologia (Campinas), 34(4), 560-570. doi:10.1590/1982-02752017000400011

Rowe, J. W., \& Kahn, R. L. (1997). Successful Aging. The Gerontologist, 37(4), 433-440. doi:10. 1093/ geront/37.4.433

Rueda, F. J. M., \& Castro, N. R. de (2013). Análise das variáveis idade e sexo no desempenho do teste de inteligência (TI). Revista Psicologia: Teoria e Prática, 15(2), 166-179. Retrieved from http://pepsic. bvsalud.org/pdf/ptp/v15n2/13.pdf

Salthouse, T. A., \& Ferrer-Caja, E. (2003). What needs to be explained to account for age-related effects on multiple cognitive variables? Psychology and $A g$ ing, 18(1), 91-110. doi:10.1037/0882-7974.18.1.91
Scheufler, L., Braz, A. C., Pacheco, J. T. B., Oliveira, C. R., Gonzatti, V., Argimon, I. I. L., Del Prette Z. A. P., \& Irigaray, T. Q. (2016). Are social skills related to sociodemographic variables and depressive symptoms? A cross-sectional study with elderly sample. Ageing International Springer, 42, 413-428. doi:10.1007/s12126-016-9260-8

Shimitz, M., \& Dorneles, B. V. (2013). O desenvolvimento Cognitivo no Ciclo Vital. In:C.L. Eizirik \& A. M. S.Bassols (Orgs.). O Ciclo Da Vida Humana: uma perspective psicodinâmica. (pp. 181-191). Porto Alegre: Artmed.

Trahan,L; Stuebing, K. K.; Hiscock M. K \& Fletcher J. M. (2014).The Flynn Effect: A Meta-analysis. Psychological Bulletin, 140(5): 1332-1360. doi:10.1037/ a0037173

Villemor-Amaral, A. E., \& Primi, R. (2009). Teste de Zulliger no Sistema Compreensivo ZSC: Forma individual. São Paulo: Casa do Psicólogo.

Zimmermann, N., Parente, M.A. M. P., Joanette, Y., \& Fonseca, R. P. (2014). Unconstrained, Phonemic and Semantic Verbal Fluency: Age and Education Effects, Norms and Discrepancies. Psicologia: Reflexão e Crítica, 27(1), 55-63. doi:10.1590/ S0102-79722014000100007

Recebido em: 05/09/2019

Reformulado em: 24/05/2020 Aprovado em: 01/09/2020 
About the authors:

Jucelaine Bier Di Domenico Grazziotin - University of Passo Fundo, Brazil. Psychologist. Ph.D. Student and M.D. in Human aging. University of Passo Fundo, Brazil. Specialization in Business Management and in Psychological assessment by the same university. Is a grantee of the institutional scholarship program at the University of Passo Fundo. Develops research in the assessment psychological context with emphasis on human aging, organizacional psychology and mental health in the interdisciplinar research and practice laboratory (LAPSI). Supervises stages of organizacional psychology and scientific initiation group. University of Passo Fundo.

ORCID: https://orcid.org/0000-0002-0147-7498

E-mail: jucelainegraz@terra.com.br

Silvana Alba Scortegagna - University of Passo Fundo, Brazil. Psychologist. Ph.D. in Psychology with area of concentration in Psychological assessment. University São Francisco, Itatiba/SP. Pos-Doctoral degree, University of São Francisco, Campinas/SP, with períod in the University of Denver/CO-USA. Professor Stricto Sensu Graduate Program in Human Aging. Develops normative and validity research with projective and selfreport tests in mental health contexts. Leader of the CNPQ research group and coordinator of the interdisciplinar research and practice laboratory (LAPSI). University of Passo Fundo.

ORCID: https://orcid.org/0000-0002-5100-6459

E-mail: silvanalba@upf.br; silvanascortegagna@gmail.com

Contact:

University of Passo Fundo

Graduate Program in Human Aging

BR 285 - Cx. Postal 611, São José

Passo Fundo-RS, Brasil

CEP: 99052-900

Phone: (054) 3316-8384 
